\title{
USO DO SCRATCH NO PROCESSO DE APRENDIZAGEM EM SALA DE AULA: RELATO DE EXPERIÊNCIAS DE ALUNOS DO MESTRADO PROFISSIONAL DE ENSINO TECNOLÓGICO/IFAM
}

\author{
A. P. F. ARAÚJO*, P. R. SOUZA e J. A. M. SILVA \\ Instituto Federal de Educação, Ciência e Tecnologia do Amazonas - IFAM \\ and_paraujo@hotmail.com*
}

Artigo submetido em outubro/2014 e aceito em dezembro/2014

DOI: $10.15628 /$ rbept.2014.3473

\section{RESUMO}

O presente trabalho teve como objetivo apresentar as contribuições dos recursos tecnológicos na formação de professores para a educação profissional a partir dos resultados de atividades de ensino envolvendo a linguagem de programação Scratch, vivenciada no contexto da disciplina Ensino e TICs do Mestrado Profissional em Ensino Tecnológico - MPET do Instituto Federal de Educação, Ciência e Tecnologia do Amazonas - IFAM, cursada no 2o Semestre do ano de 2014. A atividade seguiu uma abordagem qualitativa e o uso da técnica de revisão bibliográfica. A construção de atividades de ensino e aprendizagem a partir da linguagem de programação Scratch proporcionou trocas relevantes de saberes docentes entre os mestrandos, considerando o exercício da pesquisa, sendo evidente a complexidade de integração dos recursos tecnológicos para o ensino, que exige do educador disposição e habilidade para o uso pedagógico, sendo uma direção e uma possibilidade de inovação para o exercício da docência no ensino técnico e tecnológico.

PALAVRAS-CHAVE: formação docente; ensino profissional; recursos tecnológicos; linguagem de programação.

\section{SCRATCH THE USE IN THE PROCESS OF LEARNING IN THE CLASSROOM: REPORT OF MASTER STUDENTS EXPERIENCE PROFESSIONAL TECHNOLOGICAL / IFAM EDUCATION}

\begin{abstract}
This study aimed to present the contributions of technological resources in teacher training for vocational education from the results of teaching activities involving the Scratch programming language, experienced in the context of discipline Education and ICT Professional Master in Technological Education - MPET the Federal Institute of Education, Science and Technology Amazon IFAM, cursada in the 2 nd half year of 2014 . The activity followed a qualitative approach and the use of literature
\end{abstract}

review technique. The construction of teaching and learning activities from the Scratch programming language provided relevant exchanges of teaching knowledge among the masters, considering the exercise of the survey, it is evident the complexity of integration of technology resources for teaching, which requires the provision educator and ability for pedagogical use, with a direction and a possibility of innovation for the exercise of teaching in technical and technological education.

KEYWORDS: teacher training; vocational education; technological resources; programming language. 


\title{
1 A BUSCA POR UM REFERENCIAL TEÓRICO NA FORMAÇÃO DOCENTE
}

A formação do professor se inscreve no contexto de amplas discussões no campo teórico e das políticas públicas sendo compreendida como um importante desafio a ser enfrentado no processo de melhoria da qualidade da educação básica no contexto brasileiro, visando a construção de novas relações pedagógicas em sala de aula e a produção de novos saberes e habilidades cognitivas entre alunos e professores.

Nesse sentido, situar a questão da formação docente em nível macro das políticas educacionais é fundamental para assegurar a preparação de um profissional que no processo de sua atuação docente desenvolva sua prática em sala de aula de modo mais comprometido com a aprendizagem do aluno.

O novo paradigma educacional tem apontado à necessidade da atividade docente ultrapassar práticas de ensino verbalista, destacando que a formação crítica dos alunos deve se pautar na construção e ampliação dos saberes e conceitos científicos vinculados à relação dinâmica entre ciência, sociedade e cultura. O cenário de discussões sobre a formação docente é marcado por influência de estudos de grandes teóricos dentre eles, Gadotti que afirma:

\begin{abstract}
A formação do profissional da educação está diretamente relacionada com o enfoque, a perspectiva, a concepção mesma que se tem da sua formação e de suas funções atuais. Para nós, a formação continuada do professor deve ser concebida como reflexão, pesquisa, ação, descoberta, organização, fundamentação, revisão e construção teórica e não como mera aprendizagem de novas técnicas, atualização em novas receitas pedagógicas ou aprendizagem das últimas inovações tecnológicas (1993, p. 19).
\end{abstract}

Nesse contexto, os dispositivos legais que regulamentam a formação docente no Brasil, principalmente os fundamentos teóricos expressos nos documentos publicados pelo Ministério da Educação (MEC), como o Plano Nacional de Educação (PNE/2001), as Diretrizes Curriculares para a Formação de Professores (1999), seguiram a forte influência do conceito de professor reflexivo, um referencial que a partir da década de 90, "foi ampla e indiscriminadamente apropriado na academia e pelas políticas neoliberais de formação de professores" (PIMENTA, 2002).

A concepção de professor reflexivo inicialmente proposta por Donald Schön destaca o processo onde os professores aprendem partindo do conhecimento na ação e na interpretação de sua própria atividade, da reflexão na ação, que representa o confronto de esquemas teóricos prévios com a realidade, e da reflexão na e sobre a ação, que se constitui na própria análise da prática educativa e na troca de experiências (SACRISTÁN; PÉREZ GOMEZ, 1998).

Alarcão (2007) também nos esclarece que a noção de professor reflexivo "baseia-se na consciência da capacidade de pensamento e reflexão que caracteriza o ser humano como criativo". Dando destaque ao reconhecimento do professor como um profissional que é capaz de criar mecanismos para resolver situações problemas que enfrenta no cotidiano de sua prática docente.

As pesquisas sobre professor reflexivo se tornaram uma forte tendência na formação de professor, sendo compreendido por muitos autores como mais um modismo, mas que passou a ser severamente criticada embora busquem compreender no processo educativo a subjetividade e o profissionalismo do professor, segundo Facci (2003, p. 53) “não se preocupam em compreender 
e até mesmo não consideram as condições histórico-sociais em que a subjetividade é produzida e a profissão se desenvolve".

Mesmo considerando as contribuições de autores como Nóvoa, Donald Schön, Angel Perez Gomes, Philipp Perrenoud, Maurice Tardif, Gimeno Sacristán, Bernard Charlot, Maria Tereza Estrela, e Isabel Alarcão que passaram a produzir vários estudos concebendo a formação continuada como parte integrante da função docente, a questão da dicotomia entre a teoria e prática, que ora supervaloriza a prática em detrimento da teoria ou vice versa, é o grande desafio a ser superado na formação docente com o aprofundamento de mais estudos nesse campo.

Portanto, a busca por um referencial crítico da formação de educadores é fundamental para que os mesmos possam na prática escolar desenvolver continuamente um trabalho criativo e ressignificado a partir dos vários elementos do processo ensino-aprendizagem, tornando os sujeitos escolares, principalmente os alunos mais capacitados para enfrentar os desafios presentes e futuros do mundo em que vivem.

\subsection{Professor pesquisador: um referencial na formação continuada de professores no Ensino Tecnológico}

As inúmeras pesquisas que investigam sobre a formação de professores destacam como fundamento da atividade docente a articulação entre teorias e práticas. No Brasil, estudos de autores como Pimenta (1994), Freitas (1995), Brezinski (1998), entre outros, destacam-se nessa produção teórica. De acordo com Pimenta (2002), estudos recentes têm destacado a importância da atividade de pesquisa no âmbito da formação inicial e contínua dos professores.

Nessa perspectiva destacam-se os trabalhos de autores como Demo (1992), Pimenta (1996/99), Houssaye (1995), além dos autores como Elliot (1999), Geraldi (1999) que tem pesquisado sobre o movimento que tem sido denominado de epistemologia da prática, cujo fundamento consiste no entrelaçamento entre a "mediação entre pesquisa educacional e ação reflexiva docente, pois o profissional não pode constituir seu saber-fazer, senão a partir de seu próprio fazer" (PIMENTA, 2002).

Desse modo, a epistemologia da prática se constitui em um dos novos temas que emergem no campo conceitual e investigativo da didática e coloca em pauta a identidade do professor como pesquisador, trazendo em seu bojo, uma concepção de ensino, de professor e da pesquisa como princípio educativo, o que implica em discussões profundas sobre a natureza da ciência, o método de ensinar com pesquisa na educação básica uma vez que pesquisa é uma atividade comumente vivenciada apenas nos programas de pós-graduação.

O enfoque da pesquisa na formação docente constitui um cenário bastante desafiador na medida em que visa combinar educação e ciência. Nessa perspectiva, Demo aponta alguns caminhos para as indagações sobre como pesquisar educando e educar pesquisando:

Primeiro urge não separar os cenários, mas mesclá-los. Qualidade formal não vem antes, nem depois, nem é mais ou menos importante, ainda que qualidade formal seja da ordem dos meios e qualidade política da ordem dos fins. Produzir conhecimento pode ser exercício educativo, quando se conjugam método $e$ cidadania. Segundo, para apreciar a face educativa da pesquisa, é indispensável saber lidar com a qualidade política ou com a politicidade do conhecimento (2010, p. 19 - grifo do autor). 
Nesse sentido, o enfoque da pesquisa na formação docente atende às perspectivas do ensino tecnológico uma vez que na educação profissional os professores lidam com conteúdos de uma formação que deve atender as exigências do mercado de trabalho, destacando os avanços tecnológicos em uma sociedade cada vez mais complexa, esse aspecto em particular parece influenciar na concepção que os professores têm de seu trabalho.

Segundo Azzi (1994) a compreensão do professor, sobre o fazer pedagógico, deve ser encarado numa totalidade, na qual ocorre a articulação de diferentes áreas do saber, exigindo na formação docente uma sólida base cientifica e tecnológica, através de um processo dinâmico de apropriação e produção do conhecimento. Assim, vemos que o saber pedagógico é um saber que possibilita ao professor interagir com seus alunos na sala de aula de forma a fazer com que o professor pense no próprio ato de ensinar, refletindo sobre suas limitações pessoais, profissionais e no ambiente que atua.

Desse modo, uma atuação pedagógica que parta das questões reais e significativas vivenciadas pelos alunos entrelaçadas aos conteúdos escolares, aponta para o desafio da educação tecnológica, tendo em vista o desenvolvimento não apenas das habilidades do ser humano para o trabalho, mas de para a promoção uma reflexão sobre o significado ontológico do trabalho como meio de vida, expressão e libertação do ser humano e da sociedade em geral (FERRETI, 1999).

Nesse sentido, a concepção de trabalho que deve alicerçar a educação profissionalizante deve estar estruturada para além das perspectivas do mercado de trabalho, que está atrelado a uma concepção reducionista de formação profissional, mas, na defesa de uma educação integral do trabalhador, de forma a garantir que todo o cidadão possa ter acesso aos conhecimentos acumulados pela humanidade, valores e bens culturais do seu tempo histórico (FRIGOTTO, 2001) e, para tanto, o professor precisa compreender que seu trabalho docente constrói-se e transformase no cotidiano da vida social.

1.2 Habilidades do século XXI: um desafio para a formação dos professores no ensino tecnológico

O século XXI apresenta diferentes demandas, a ênfase na aprendizagem de novas habilidades em virtude do poder de comunicação humana que tem sido ampliado de modo cada vez mais crescente com o desenvolvimento das ferramentas tecnológicas no contexto social, fazendo surgir novas modalidades de comunicação social, com a possibilidade de aproximação e interação instantânea entre pessoas de todo o mundo.

Essas mudanças têm interferido em vários campos como a economia, a medicina, a engenharia, porém, aos poucos vem despertando interesses dos pesquisadores do campo educacional, sobre as possibilidades de uso e adequação pedagógica como recurso eficaz para mobilizar a produção de conhecimento e aprendizagem de modo criativo e colaborativo.

O movimento em defesa do uso dos recursos tecnológicos no contexto escolar advém dos desafios das mudanças qualitativas que tanto se espera que sejam efetivadas nas práticas escolares, na perspectiva de que se altere o atual panorama em que ocorre processo ensinoaprendizagem, historicamente pautado na ênfase da transmissão e memorização dos conteúdos escolares. 
A inserção das tecnologias digitais nos processos de ensino e aprendizagem promove uma atuação diferenciada do professor em sala de aula, que passa a assumir o papel de mediador, favorecendo o diálogo e a participação ativa dos estudantes no processo de construção de conhecimentos. De acordo com Masetto (2000, p. 31), "a utilização dos dispositivos de comunicação implica tanto na aquisição de habilidades e competências comunicativas por parte dos docentes, como dos discentes uma vez que a aprendizagem ocorre de modo participativo".

Segundo Lévi (1999), no contexto das tecnologias educativas o professor passa a dispor não somente do livro e do quadro branco, mas de diversos dispositivos de comunicação como chats, fóruns, blogs, videoblogs, entre outros, os quais exigem habilidades mediadoras diferenciadas e propiciam estratégias pedagógicas que exigem interação, intervenção e colaboração para a construção coletiva do conhecimento.

Em especial, a fluência tecnológica chama atenção para a presença e a influência que a tecnologia da informação e do conhecimento (TICs) tem hoje na sociedade contemporânea e consequentemente no contexto educacional e isso, sem dúvida, exige um aprimoramento na prática dos professores.

A fluência tecnológica pode ser entendida como dar conta de empreitadas não-lineares interpretativas, nas quais a postura é de sujeito participativo/reconstrutivo (DEMO, 2008). E o que significa o professor ter fluência tecnológica? Significa compreender tudo o que a máquina/computador pode oferecer. É ter critérios para selecionar a tecnologia para os processos de ensino e aprendizagem sem recair no "engole sem pensar". É pensar que para promover a aprendizagem dos alunos, é fundamental buscar, pesquisar e aprender a aprender continuamente, olhando para a própria trajetória profissional, perceber falhas, saber o que ainda falta aprender e assumir o desafio de ser melhor a cada dia.

De fato, as novas habilidades requeridas pelo século XXI tornam cada vez mais evidente que não é mais possível dar aulas apenas com o que foi aprendido na graduação, ou achar que a tecnologia é coisa para especialistas. Trabalhar em equipe, trocar experiências e utilizar tudo o que se pode obter de um recurso tecnológico são atitudes quando se pensa no cenário da sociedade intensiva do conhecimento (DEMO, 2010)

A importância de o professor exercer o domínio sobre as tecnologias favorece o estabelecimento de novas conexões no ensino que se sobrepõem ao livro didático (PIVA JR, 2013), sendo um recurso fundamental na construção de novas perspectivas para o ensino escolar e a superação das concepções científicas "distorcidas" que os alunos, nos diversos níveis de ensino, frequentemente comungam no senso comum.

O uso do computador é encarado como suporte para a concretização do processo educacional, com a contribuição de software, que reúne um conjunto de instruções préprogramadas e, potencialmente auxiliam no desenvolvimento de habilidades lógicas e cognitivas através da resolução de problemas e uso da criatividade.

Os softwares têm evoluído sobremaneira com programações específicas para uso educacional, com linguagens cada vez mais visuais dinâmicas e com fortes efeitos sonoros. De acordo com Piva Jr (2013), os softwares estão divididos em exercício e prática, tutoriais, jogos, educacionais, de simulação, resolução de problemas, pacotes utilitários e ferramentas de referência. 
Sobre o uso de programas de simulação no ensino, Vieira (2001) menciona sua contribuição enquanto recurso "para que a aprendizagem se processe num ambiente onde o aprendiz se envolva com o fenômeno e o experiencie, levantando suas hipóteses, buscando outras fontes de informações e usando o computador para validar sua compreensão do fenômeno".

Desse modo, a fluência tecnológica docente implica na habilidade de selecionar dentre as inúmeras possibilidades de uso dos recursos e ferramentas tecnológicas, selecionar aquelas que melhor se adequam aos objetivos de aprendizagem pretendidos na mediação pedagógica, havendo sempre um planejamento prévio e organizados das atividades pedagógicas.

\section{METODOLOGIA}

Este trabalho apresenta um relato de experiência de um trabalho desenvolvido na disciplina Ensino e TICs do Mestrado Profissional em Ensino Tecnológico - MPET do Instituto Federal de Educação, Ciência e Tecnologia do Amazonas - IFAM, cursada no 2ㅇ Semestre do ano de 2014, com o objetivo de contribuir com a formação de profissionais e pesquisadores que atuem no ensino técnico e tecnológico, focalizando os aspectos tecnológicos e científicos na formação do educador para atender as perspectivas da educação do século XXI, cujo pilar é aprender a aprender no contexto das demandas da sociedade intensiva do conhecimento e da produção tecnológica.

Neste artigo, são explicitados os resultados de uma atividade de elaboração a partir da ferramenta Scratch, surgida no contexto da referida disciplina cujas discussões empreendidas, destacavam dentre outras questões, identificar os blocos de construções básicas da linguagem de programação e construir programas utilizando Scratch para resolução dos problemas.

A atividade seguiu uma abordagem qualitativa que de acordo com Minayo (2001), "trabalha com o universo de significados, motivos, aspirações, crenças, valores e atitudes, o que corresponde a um espaço mais profundo das relações, dos processos e dos fenômenos que não podem ser reduzidos à operacionalização de variáveis". Havendo planejamento prévio da atividade de ensino relacionada a um componente curricular da educação básica, envolvendo o uso da ferramenta tecnológica, captura de imagem, som elaborados autonomamente pelos alunos e/ou disponíveis na internet.

Foi utilizada, a técnica de revisão bibliográfica que conforme mencionam Gerhardt e Silveira (2009, p. 37) "é feita a partir do levantamento de referências teóricas já analisadas, e publicadas por meios escritos e eletrônicos, como livros, artigos científicos, páginas de web sites". A construção da atividade a partir da linguagem de programação Scratch proporcionou trocas relevantes de saberes docentes entre os mestrandos, considerando o exercício da pesquisa e possibilidade de aplicação didática da estratégia pedagógica nos diversos níveis de ensino visando à instrumentalização do aluno na construção do conhecimento científico e formação profissional, bem como na sua efetiva participação na sociedade em que está inserido.

\section{CONTRIBUIÇÃO DOS RECURSOS TECNOLÓGICOS NA FORMAÇÃO DE PROFESSORES PARA A EDUCAÇÃO PROFISSIONAL.}

A disciplina Ensino e TICs no conjunto das discussões sobre a inovação na educação, por meio da produção científica de autores como John Biggs e Catherine Tang (2011); Demo (2008), 
Moran (2013), ressaltou no processo de formação docente os fundamentos da educação do século $X X I$, um tema que se encontra em amplo debate no mundo acadêmico nacional e, principalmente, internacional, sobre a importância da escola favorecer ao aluno a aprendizagem autônoma, a capacidade de resolução de problemas em grupos colaborativos e o pensamento computacional, a partir de roteiros de aprendizagens elaborados numa perspectiva do alinhamento construtivo, um modelo de planejamento de ensino proposto pelo psicólogo educacional John Biggs.

De acordo com Biggs (2003) neste modelo de ensino o aluno constrói sua própria aprendizagem por meio de atividades de aprendizagem relevantes. $O$ trabalho do professor é criar um ambiente de aprendizagem que apoia as atividades de aprendizagem e que estas estejam adequadas para alcançar os resultados de aprendizagem desejados. A chave do alinhamento é que todos os componentes do sistema de ensino - atividades de ensino, atividades de aprendizagem e tarefas de avaliação estejam alinhados uns com os outros.

Durante o desenvolvimento da disciplina foi vivenciada uma experiência que permitiu o uso de ferramenta digital por professores em formação do MPET-IFAM, visando a pesquisa sobre as possibilidades pedagógicas a serem desenvolvidas a partir do Scratch e as novas competências e habilidades que podem ser mobilizadas no processo de ensino e aprendizagem. Tais competências e habilidades estão, primordialmente, vinculadas às esferas: pedagógica (relacionada à utilização de recursos discursivos facilitadores da aprendizagem), gerencial (concernente aos procedimentos estruturais para o desenvolvimento de atividades educacionais) e técnica (ligada à transparência tecnológica do conjunto formado pelo sistema, software e interface selecionados).

Zabala e Arnau (2010) afirmam que no século atual não é mais suficiente nem para o aluno e muito menos ao professor adquirir alguns conhecimentos ou dominar algumas técnicas, apesar de ser de forma compreensiva e funcional. Se faz necessário cada vez mais que todos sejam cognitivamente capazes, e sobretudo, em outras capacidades: motoras, de equilíbrio, de autonomia pessoal e de inserção social. Não é suficiente saber ou dominar uma técnica, nem é suficiente sua compreensão ou funcionalidade, é necessário que o que se aprende sirva para poder agir de forma eficiente e determinada diante de uma situação real. E é nisso que professor e aluno devem estar envolvidos.

Dentro desta perspectiva foi proposto aos alunos do MPET/IFAM uma situação de aprendizagem de programação, que foi realizada em dupla, utilizando Scratch. Vale ressaltar que atualmente, programação é apontada como uma habilidade tão essencial como leitura e matemática. Scratch, por sua vez, é uma linguagem de programação que permite a criação de programas, jogos, animações e etc. Criada por Mitchel Resnick do MIT Media Lab, Scratch é muito mais acessível que outras linguagens de programação por se utilizar de uma interface gráfica que permite que programas sejam criados como blocos de montar, lembrando o brinquedo Lego.

O Scratch é uma linguagem visual de programação que possui uma boa usabilidade para o usuário uma vez que seu funcionamento ocorre por meio de blocos de estruturas de programação, sem a necessidade de se digitar nenhum código para programar e resolver os problemas propostos, a saber: a criação de histórias interativas, animações, simulações, jogo, músicas, apresentações animadas, entre outros. 


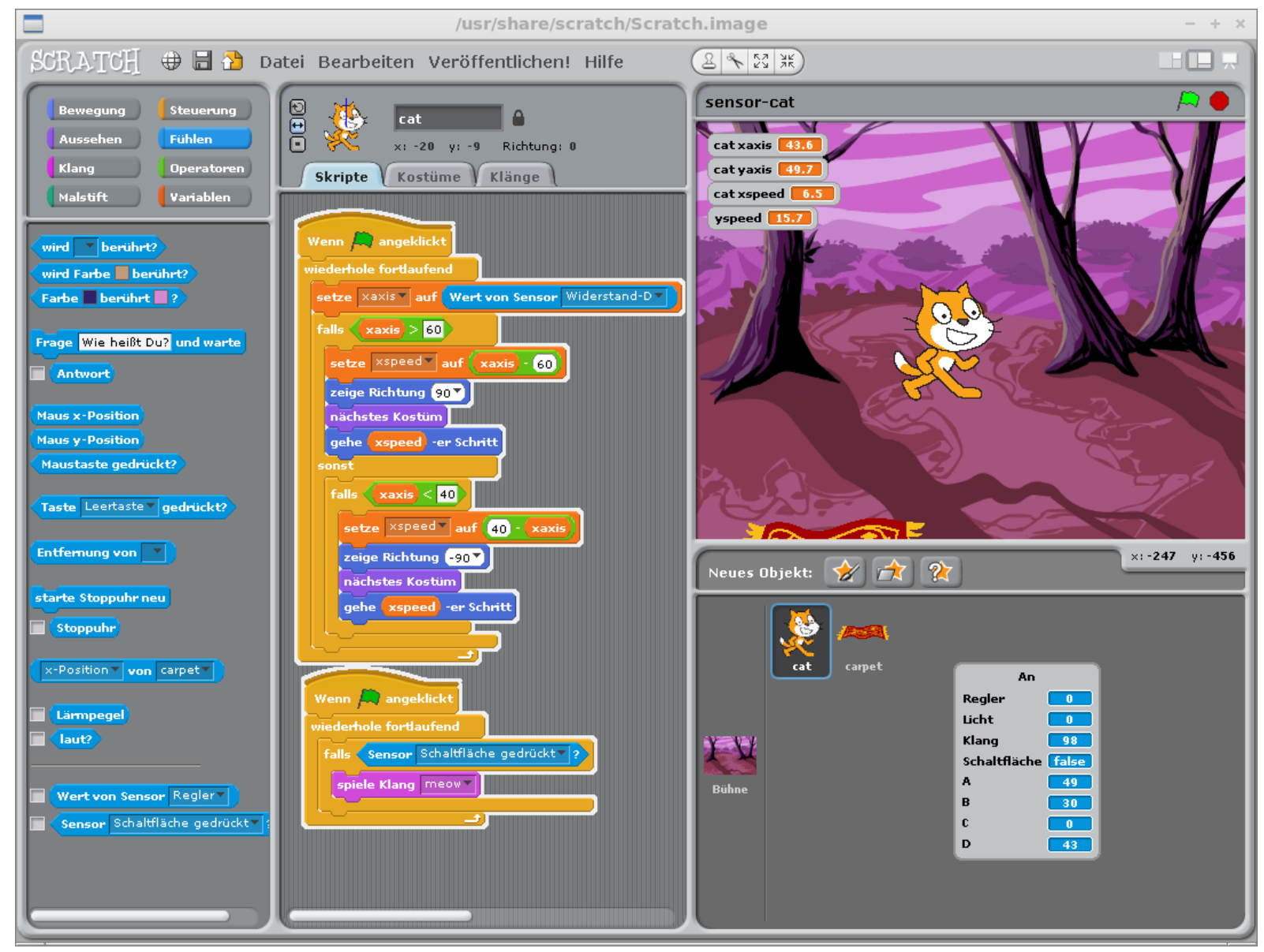

Figura 1 - Área de Trabalho do Scratch.

Fonte: http://goo.gl/uhEBaO.

A partir de tutoriais disponíveis na internet sobre o uso da ferramenta scratch, conforme o plano de aula proposto, os alunos deveriam investigar sobre experiências de ensino e aprendizagem com utilização do Scratch em algum nível de ensino e implementar um projeto de sua preferência (sobre pequenos jogo, animação ou um programa para cálculo) destacando o propósito do uso do Scratch, nível de ensino, disciplina curricular, habilidades a serem desenvolvidas e resultados de aprendizagem pretendidos. Ao concluir, o arquivo deveria se compartilhado com a comunidade no site do Scratch ${ }^{1}$ ou no YouTube.

Ao usar o Scratch os alunos do MPET/FAM entraram em contato com uma proposta de aprendizagem motivadora e isso favoreceu o seu enfoque mais profundo para os conceitos matemáticos que foram apreendidos oportunamente através da pesquisa e do desafio de elaborar aulas a partir da ferramenta. Na perspectiva do alinhamento construtivo, o plano de aula envolvia 14 questões desafiadoras para exploração da programação com o Scratch.

As questões foram propostas com o intuito de domínio dos comandos disponíveis na interface do Scratch, denominados de blocos correspondentes podem ser combinados e agrupados, bem como das ferramentas de acesso rápido para edição das animações presentes no palco onde é possível ver os resultados das animações desenvolvidas. A figura 2 demonstra a construção de uma animação com um Sprite efetuando diversos movimentos.

\footnotetext{
${ }^{1}$ Disponível em: http://scratch.mit.edu/.
} 


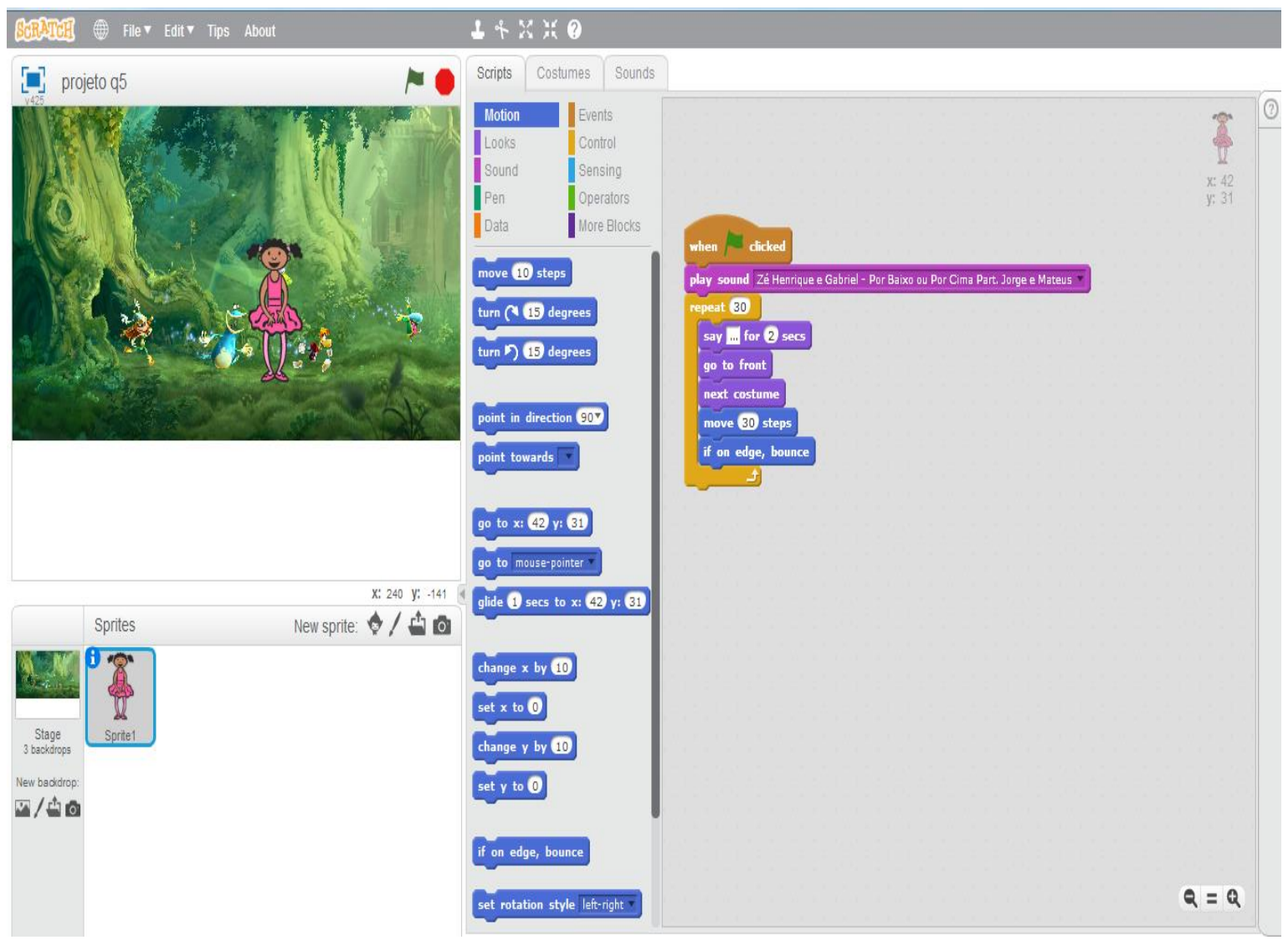

Figura 2 - Atividade envolvendo som e animação de um sprite na interface do Scratch. Fonte: Próprio autor.

As Figura 3 e 4 ilustram outra atividade proposta, sobre a elaboração de uma animação para mostrar uma lâmpada acender e apagar para o usuário clicar com o mouse sobre um interruptor.

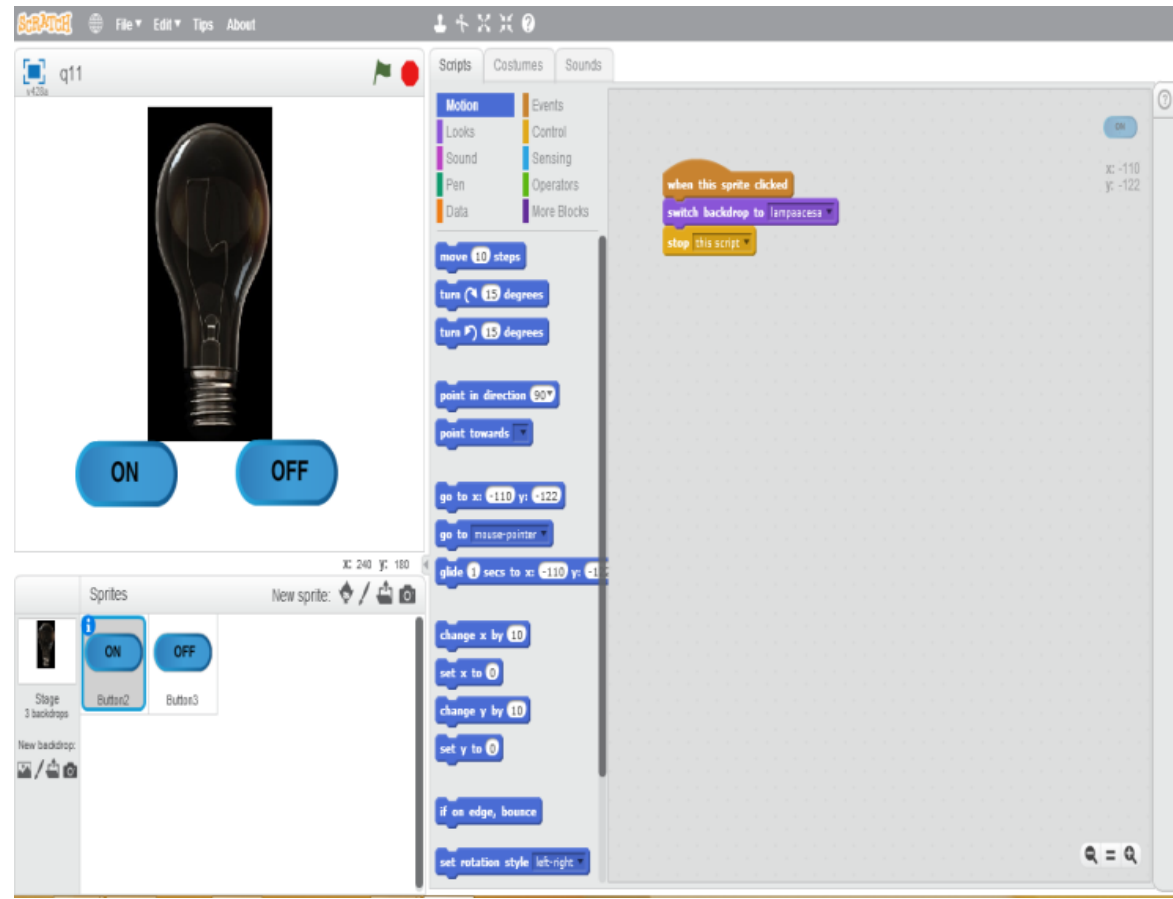

Figura 3 - Área de Trabalho do Scratch - Atividade Fonte: Próprio autor. 


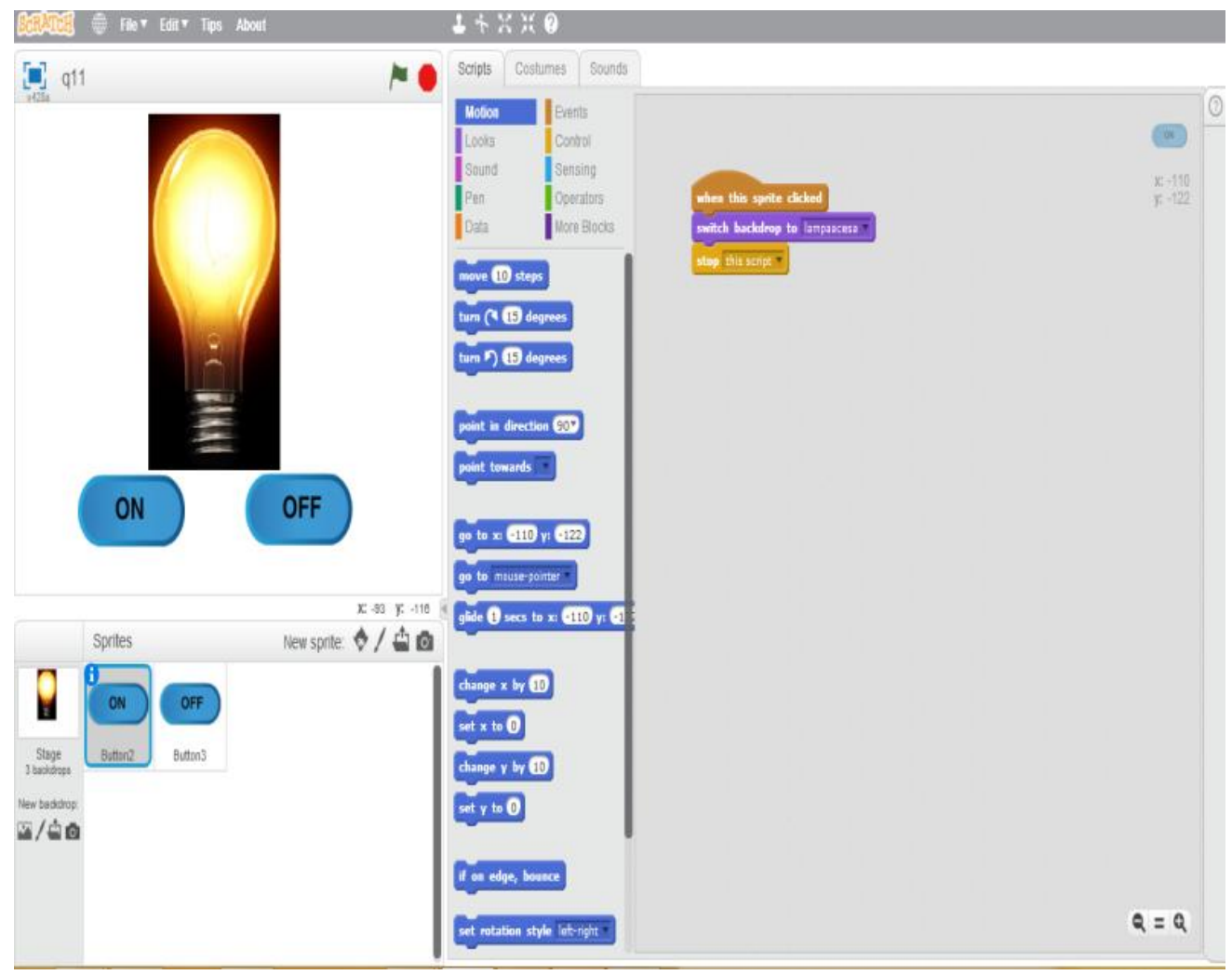

Figura 4 - Área de Trabalho do Scratch - Atividade

Fonte: Próprio autor.

No decorrer da execução da atividade, observou-se que o uso do Scratch valoriza a autoaprendizagem, incentiva a formação permanente, a pesquisa de informações básicas e das novas informações, o debate, a discussão, o diálogo, o registro de documentos, a elaboração de trabalhos, a construção da reflexão pessoal, e se assim pode-se dizer: a aprendizagem por contatos ou aprendizagem colaborativa. Contextos estes, vivenciados pelo grupo de mestrando na construção das etapas da atividade, onde diante das dúvidas surgidas face aos comandos da linguagem de programação, os questionamentos, as trocas de informações e socialização das descobertas compunham o clima de trabalho e aprendizagem em sala de aula.

Destaca-se também nesta experiência que os alunos exercitaram a reflexão na ação e sobre a ação, no desenvolvimento das atividades, pois todas as tarefas propostas com o uso do Scratch ajudaram a dar significado para teorias e os conceitos abordados, integrando-os ao mundo intelectual de todos os mestrandos, permitindo ainda, o levantamento de questões sobre acesso, dificuldades e possibilidades de adequar ao ensino o uso de ferramentas digitais e interativas em sala de aula com os alunos de diversos níveis de formação.

\section{ALGUMAS CONSIDERAÇÕES}

Com a atividade de programação os alunos do MPET/IFAM puderam perceber que fazer uso de um recurso tecnológico para a aprendizagem não é tarefa fácil, porém é uma experiência motivadora, sendo reconhecida a importância do uso das tecnologias associado à Pedagogia, uma combinação com potencial relevante, no que se refere à motivação para pesquisar e aprender novos conceitos e habilidades, onde o trabalho ocorre de forma colaborativa e a construção do conhecimento ocorre de forma divertida e inovadora. Sendo que, a experiência com o uso do 
Scratch proporcionou a vivência da função de pesquisadores, programadores, editores, leitores, no compartilhamento de conhecimentos que se constitui num caminho para o exercício da docência no ensino técnico e tecnológico.

As rápidas transformações de nossa atual sociedade e as discussões apontadas pelos avanços tecnológicos apresentados neste relato de experiência mostram a necessidade de uma reestruturação da prática de ensino, a ser implementada por uma reflexão crítica sobre o trabalho do professor em sala de aula para uma efetiva integração dos recursos e ambientes digitais no processo de ensino. Este trabalho destacou uma experiência relacionada ao desenvolvimento de novas competências docentes no ensino tecnológico e diante dos resultados positivos adquiridos aponta para a possibilidade de se ampliar cada vez mais os estudos acadêmicos que priorizem a tecnologia educacional e sua incorporação no currículo e no processo de formação de professores uma que esta tende a ser um caminho ou uma perspectiva metodológica possível para ressignificar os processos de ensino e aprendizagem nos diversos níveis e modalidades de formação humana.

\section{REFERÊNCIAS}

1. ALARCÃO, Isabel. Professores reflexivos em uma escola reflexiva. São Paulo: Cortez, 2007.

2. AZZI, Sandra. Da autonomia negada à autonomia possível. Trabalho docente na escola pública capitalista: um estudo a partir da sala de aula. São Paulo: USP, em 1994. Tese de doutorado. Faculdade de Educação da Universidade de São Paulo.

3. BIGGS, J. Teaching for Quality Learning at University, 2nd Edition, The Society for Researchinto Higher Education \& Open University Press (2003).

4. BIGGS, John. Teaching and Learning in Higher Education: New Trends and Innovations. University of Aveiro, 13-17 April, 2003. Disponível em: <http://goo.gl/uMJoLl>. Acesso em: 04 jun 2015.

5. DEMO, Pedro. Educação e Alfabetização científica. Campinas, SP: Papirus, 2010. (Coleção Papirus Educação).

6. Habilidades do Século XXI. B. Téc. Senac: a R. Educ. Prof., Rio de Janeiro, v. 34, n.2, maio/ago. 2008. Disponível em: <http://goo.gl/xfXs0>. Acesso em: 16 out 2015.

7. FACCI, Marilda Gonçalves Dias. Valorização ou esvaziamento do trabalho do professor? Um estudo crítico comparativo da teoria do professor reflexivo, do construtivismo e da psicologia vigotskiana. (Tese de doutorado) Araraquara: UNESP/FCLAR, 2003.

8. FERRETI, Celso J., João dos Reis S. Junior e Maria Rita Oliveira (Orgs). Trabalho, formação e currículo: para onde vai a escola? São Paulo: Xanã, 1999.

9. FRIGOTTO, G; CIAVATTA. M. (orgs.). Teoria e Educação no Labirinto do Capital. RJ, Vozes, 2001.

10. GADOTTI, Moacir. Diversidade cultural e educação para todos. Rio de Janeiro: Graal, 1992.

11. Escola Cidadã. 2a ed. São Paulo; Cortez, 1993.

12. GERHARDT. Tatiana Engel; SILVEIRA. Denise Tolfo. Métodos de pesquisa. (organizadoras). Universidade Aberta do Brasil - UAB/UFRGS e pelo Curso de Graduação Tecnológica Planejamento e Gestão para o Desenvolvimento Rural da SEAD/UFRGS. - Porto Alegre: Editora da UFRGS, 2009. 
13. LÉVI, Pierre. Cibercultura. Tradução de Carlos Irineu da Costa. São Paulo: Ed. 34, 1999.

14. MASETTO, Marcos T.; BEHRENS, M. A. Novas tecnologias e mediação pedagógica. Campinas: Papirus, 2000.

15. MINAYO, Maria. C. S. Ciência, técnica e arte: o desafio da pesquisa social. In: MINAYO, Maria. C. S (Org.). Pesquisa social: teoria, método e criatividade. Petrópolis, RJ: Vozes, 2001. p.09-29.

16. PIMENTA, S. G. Professor Reflexivo: construindo uma crítica. In PIMENTA, \& GHEDIN, (orgs.) Professor reflexivo no Brasil: gênese e crítica de um conceito. São Paulo: Cortez Ed, 2002 (1a edição: junho de 2002; 2ª edição: novembro de 2002): 12-52.

17. PIVA JR. Dilermano. Sala de aula digital: uma introdução à cultura digital para educadores. 1ạ ed. São Paulo: Saraiva, 2013.

18. SACRISTÁN, J.G. e PÉREZ GÓMEZ, A.I. Compreender e Transformar o Ensino. Porto Alegre: Art Med, 1998. Tradução: Ernani F. da Fonseca Rosa.

19. VIEIRA, F. M. S. Avaliação de software educativo: reflexões para uma análise criteriosa. Disponível em:< http://goo.gl/hHHnBt >. Acesso em:12 fev 2015.

20. ZABALA, Antoni; ARNAU, Laia. Como aprender e ensinar competências. Porto Alegre: Artmed, 2010. 